\title{
Friction and Wear Behaviors of Gear Steel under Coupling of Rolling and Sliding
}

\author{
Ding Ming*
}

Xuzhou Institute of Technology, Xuzhou 221008, China

\begin{abstract}
In this paper, the gear material 20CrMnTi was selected as the research object. Friction and wear behavior was performed on the M2000 friction and abrasion tester. The friction and wear mechanisms of 20CrMnTi steel were discussed under coupling of rolling and sliding. The results show that damage of steel-steel couples under coupling of rolling and sliding is caused by the interaction of mechanical fatigue with dynamical phenomena of rolling and sliding friction. Lubrication directly determines the friction and wear behaviors. Under dry friction, the wear mechanisms of 20CrMnTi steel are mainly adhesive wear, abrasive wear, oxidation wear and fatigue pitting under dry friction. Under lubricating conditions, the wear mechanism of $20 \mathrm{CrMnTi}$ steel is mainly surface fatigue wear.
\end{abstract}

Keywords: 20CrMnTi, gear, friction and wear, rolling and sliding.

\section{INTRODUCTION}

In the mechanical transmission, such rolling friction pair under alternating load as gears and bearings is the key part in a machine. Gear transmission is widely used, in which the gear plays a main role. Therefore, the life span of a gear determines the efficiency of mechanical transmission [1]. When the gear friction pair rolls under the contacting condition, it has a sliding speed, which causes and transmits alternating load. The load under coupling of rolling and sliding is a complicated process influenced by tribological load set and material properties, falling into the category of "the science of wear fatigue damage and inefficiency of loaded wear pair system in the machines and equipments" [2]. In such mining equipments as the reduction boxes of coal mining machines and boring machines, the gear is responsible for transmitting the torque of cutting motor to cutting drum. When the drum coals, the gear with complex alternating loads not only bears engaging force, but adjusts timely rotational speed. The gear transmission speed of reduction box is very low $(\mathrm{v} \leq 1 \sim 2 \mathrm{~m} / \mathrm{s})$ and the tooth surface contact stress is very high ( $\sigma \geq 500 \mathrm{Mpa})$, so its gear belongs to low-speed and heavy-duty one [3]. Because of hard working conditions, short downtime and bad lubricating conditions, the spare parts cannot be well lubricated or maintained. So it results from serious gear wear and failure in reduction boxes of mining equipments [4].

According to Zhu Longgen et al. [5] who have studied the wear of low-speed and heavy-duty gear with peripheral speed of $1 \sim 4 \mathrm{~m} / \mathrm{s}$, if $\mathrm{v}$ is between $1 \sim 4 \mathrm{~m} / \mathrm{s}$, the gear has some certain tooth surface wear, whose wear rate is influenced by peripheral speed and has the worst speed (1.13 $\sim 1.41 \mathrm{~m} / \mathrm{s}$ ), during which the wear rate is highest.
According to Ge Shirong et al. [6] who have tribologically designed the main reducer of the tunnel boring machine, the low-speed and heavy-duty gear is in boundary lubrication, hosted by boundary film. So circulating lubrication can replace oil lubrication. According to Zhu Xun [7] who has discussed the wear mechanism of low-speed and heavy-duty gear in boundary lubrication, the wear behavior is greatly influenced by tooth surface hardness, and hence the more the hardness is, the less the gear wear. Liu Weimin et al. [8] have studied the influence of friction coefficient on the life of gear contact fatigue. The fatigue life of friction pair with low friction coefficient is long, which indicates friction coefficient is a key element to influence fatigue life. Though many scholars have studied low-speed and heavy-duty gear, few have touched friction fatigue behavior of $20 \mathrm{CrMnTi}$ steel friction pair under coupling of rolling and sliding.

This paper selects the gear material $20 \mathrm{CrMnTi}$ as the research object, makes an experiment of friction and wear under dry friction and lubrication and discusses friction fatigue behavior of $20 \mathrm{CrMnTi}$ steel friction pair under coupling of rolling and sliding to acquire the wear fatigue damage mechanism of low-speed and heavy-duty gear and provide theoretical foundation for its tribological design.

\section{SAMPLE PREPARATION AND TEST METHOD}

\subsection{Experimental Materials}

The sample is steel ring, with outer diameter $30 \mathrm{~mm}$, inter diameter $16 \mathrm{~mm}$ and thickness $10 \mathrm{~mm}$. The experimental material is $20 \mathrm{CrMnTi}$ which is mainly used as transmitting parts in mining machines. In China, $20 \mathrm{CrMnTi}$ gear steel has good wear resistance and toughness and can withstand impact, bending and contact stress. It is dominated in production and consumption. Table $\mathbf{1}$ sees its physical and mechanical properties. 
Table 1. Physical and mechanical properties of 20 CrMnTi.

\begin{tabular}{|c|c|c|c|c|}
\hline Material & Tensile Strength (MPa) & Yield Strength (MPa) & Elastic Modulus (GPa) & Poisson's Ratio \\
\hline \hline $20 \mathrm{CrMnTi}$ & 1080 & 835 & 207 & 0.25 \\
\hline
\end{tabular}

To disclose wear fatigue damage mechanism of lowspeed and heavy-duty gear's tooth surface, $20 \mathrm{CrMnTi}$ steel ring is carburized. The parameters of heat treatment process are as follows: carburizing is at $920^{\circ} \mathrm{C}$ and the layer is between $0.4 \sim 0.8 \mathrm{~mm}$; the quenching is at $800^{\circ} \mathrm{C}$ in the saltbath furnace by oil cooling; its tempering is at $180^{\circ} \mathrm{C}$; after one-hour thermal insulation, it is air cooled. The surface hardness can arrive at 60 65 HRC, satisfying the requirements of low-speed and heavy-duty gear on hardness. The initial roughness of the steel ring's surface is $R a=1 \mu \mathrm{m}$.

\subsection{Experimental Apparatus and Parameters}

During the movement of low-speed and heavy-duty gear, pure rolling only exists in the node location of tooth surface and other meshed positions have sliding speed ratio. To simulate working conditions of the reduction box with lowspeed and heavy-duty gear, the $\mathrm{n}$ of upper gear is $180 \mathrm{r} / \mathrm{min}$, the lower is $200 \mathrm{r} / \mathrm{min}$, and their sliding speed ratio is $10 \%$. Then the friction between the upper ring and the lower one is that under coupling of rolling and sliding. Closed gear oil LCKC220 is used for oil lubrication, with properties shown in Table 2.
During the experiment, the roughness value of the upper ring is measured by surface roughness tester, with once every one hour by dry friction and once every five hours by oil lubrication. During dry fiction, the wear amount is weighed five times altogether, with one hour considered as one period. During oil lubrication, five hours is considered as one period and the whole process is classified into 10 periods. The temperature of the friction pair in wearing process is measured by the infrared thermal imager and the wear profile is shot by optical microscope.

\section{RESULT AND DISCUSSION}

\subsection{Variation of Friction Coefficient and Friction Pair Temperature}

Fig. (2) shows the curve of friction coefficient and the curve of friction pair temperature change of the upper samples under dry friction and oil lubrication condition under coupling of rolling and sliding. Under dry friction condition, the friction pair temperature quickly rises to $65^{\circ} \mathrm{C}$, then with the extension of time, the temperature remains stable, and the corresponding friction coefficient also

Table 2. Properties of closed gear oil L-CKC220.

\begin{tabular}{|c|c|c|c|c|}
\hline Name & Kinematic Viscosity $\left(\mathbf{4 0}{ }^{\circ} \mathbf{C}\right) \mathbf{~ m m}^{2} / \mathbf{s}$ & Flash Point $\left({ }^{\circ} \mathbf{C}\right)$ & Pour Point $\left({ }^{\circ} \mathbf{C}\right)$ & Total Separated Water $(\mathbf{m l})$ \\
\hline \hline L-CKC220 & 222.1 & 243 & -20 & 80.1 \\
\hline
\end{tabular}

Friction and wear behavior of the two rings are performed on the M2000 friction and abrasion tester. The experimental apparatus is shown as in Fig. (1) and the parameters are shown in Table $\mathbf{3}$.

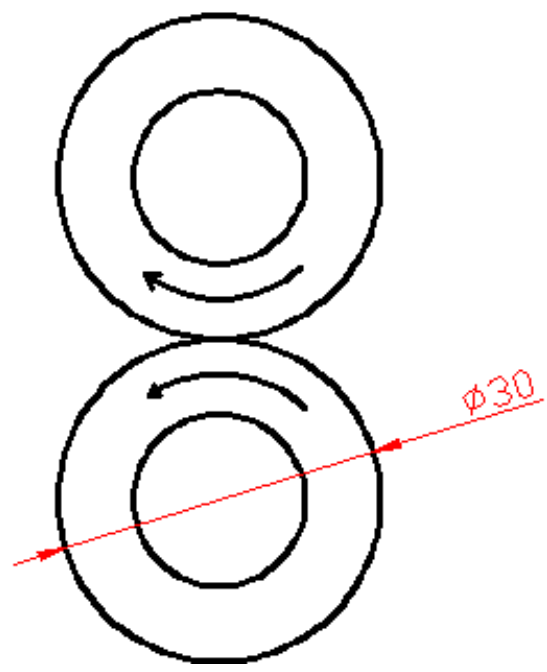

Fig. (1). Schematic diagram of friction and wear of experimental steel-steel frication pair.
Table 3. Experimental parameters of friction under coupling of rolling and sliding.

\begin{tabular}{|c|c|}
\hline Parameters & Numerical Value \\
\hline \hline Experimental loading & $1200 \mathrm{~N}$ \\
\hline Speed & The lower is $200 \mathrm{r} / \mathrm{min}$, the upper $180 \mathrm{r} / \mathrm{min}$ \\
\hline Time & $1 \mathrm{~h}, 2 \mathrm{~h}, 3 \mathrm{~h}$ and so on \\
\hline Material & $20 \mathrm{CrMnTi}$ \\
\hline Sliding ratio & $10 \%$ \\
\hline Lubrication & Dry friction and oil lubrication \\
\hline
\end{tabular}

increases obviously as the temperature rises, then begins to decline in the stable value. Under dry friction condition, the friction pair surfaces are in direct contact, and micro-peaks shear and plough each other, thus cause the adhesive wear, resulting in elevated temperatures. In turn, the high temperature causes the oxidation wear on the friction pair surfaces, and the oxide particles remain in the surface of the friction pair, increase friction shear and plough. Such vicious circle continues until the impact velocity of the micro-peaks of the friction decreases as well as the friction dissipation 
energy decreases, entering the steady wear. Under oil lubrication condition, the friction pair temperature slowly rises to $30^{\circ} \mathrm{C}$ and remains stable. Because under the condition of oil lubrication, the heat caused by friction and heat energy generated by sliding friction force are taken away by oil, at the same time, the oil is fully covered in the friction pair to prevent oxidation of friction pair surface, resulting in the limited temperature rise.

It's obvious that lubrication condition has great influence on the friction coefficient and friction temperature. The boundary lubrication of the low speed and heavy load gear should be strengthened with the lubrication oil containing extreme pressure and antiwear additives to improve the boundary films strength and the lubrication state, to avoid the direct contact between the tooth surface, to reduce the gear fatigue wear damage and to prolong operating life.

\subsection{The Relationship Between Wear Value and Friction and Wear Behavior}

Fig. (3) shows the wear value change of the upper samples under dry friction and oil lubrication condition under coupling of rolling and sliding. As is seen from the figure, under dry friction condition, when it is in the $2^{\text {nd }}$ hour, the wear value has increased dramatically between the $1^{\text {st }}$ and $2^{\text {nd }}$ hour, then, the value grows slowly and gradually becomes stable with the average value $70 \mathrm{mg}$. Under oil lubrication, wear value changes slowly, and there are little differences in each time with the average value about $1 \mathrm{mg}$, which shows minor wear. It is concluded in this paper that under dry friction condition, initially metal and metal directly contact, and under the condition of contact stresses, the micro-peaks plough and shear, thus generates large abrasive dust. Under the dry friction condition, that is, seriously bad of lubrication, abrasive dusts cannot be eliminated or taken away, and wear surface further develops into abrasive wear. Under the condition of good lubrication, abrasive dusts can be taken away by the lubricants and

(a) Friction pair temperature

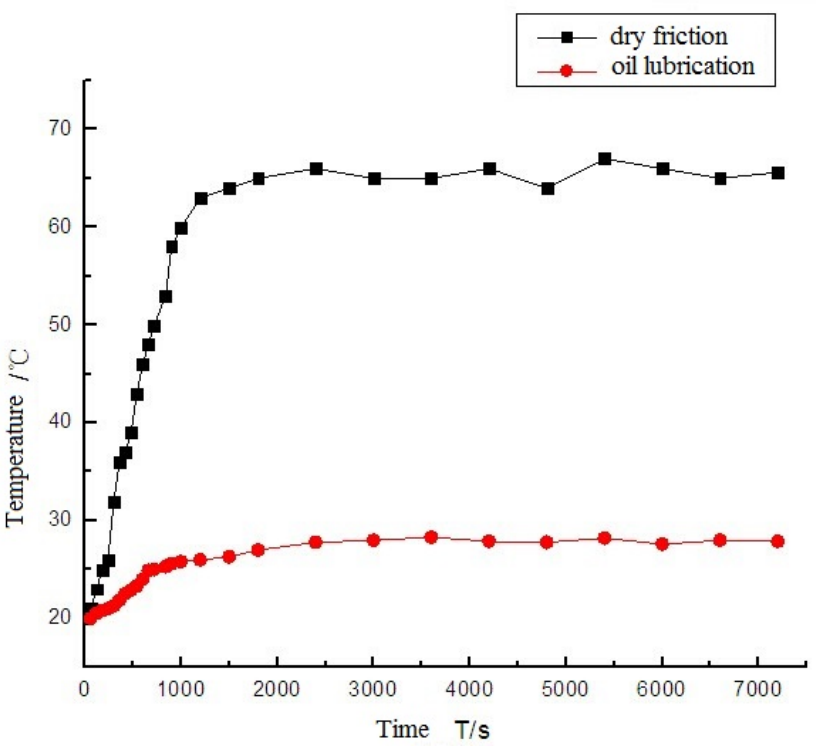

abrasive wear is reduced, and after a period of wear, the wear tends to be stable with few wear value change in each stage

\subsection{The Relationship Between Surface Roughness and Friction and Wear Behavior}

Fig. (4) shows the surface roughness change of the upper samples under dry friction and oil lubrication condition under coupling of rolling and sliding. Under dry friction condition, the surface roughness curve rises sharply, and wear value and friction coefficient increase correspondingly. When the wear time is over 3 hours, the surface roughness decreases gradually, and then becomes stable. Under oil lubrication condition, the surface roughness value changes between $0.9-1.2 \mu \mathrm{m}$, and the curve almost appears as a horizontal line with small changes. It is concluded in this paper that under dry friction condition, due to the direct contact between metals, the micro-peaks of surface shear and plough each other, resulting in uneven surface and serious wear, leading to increase of roughness. When the roughness value rises, according to physical and chemical point of view, atoms in the rough region have higher energy and surface energy than the atoms with normal adjacent atoms. It's easy to cause the apparent defects, which increase the direct contact between metals area, resulting in greater adhesion, faster metal movement, adhesive wear and fatigue spalling, thus leads to friction pair wear and fatigue damage, and the most direct manifestation is the increase of wear volume and friction coefficient. Under oil lubrication condition, the surface of friction pair is covered by lubricating oil, so whether the formation of adsorption membrane or reactor membrane, maintains a dynamic balance, causing slight metal surface wear and little effect on surface roughness value.

\subsection{The Wear Mechanism Analysis}

Fig. (5) shows the wear morphology of the upper samples under dry friction condition and oil lubrication condition

(b) Friction coefficient

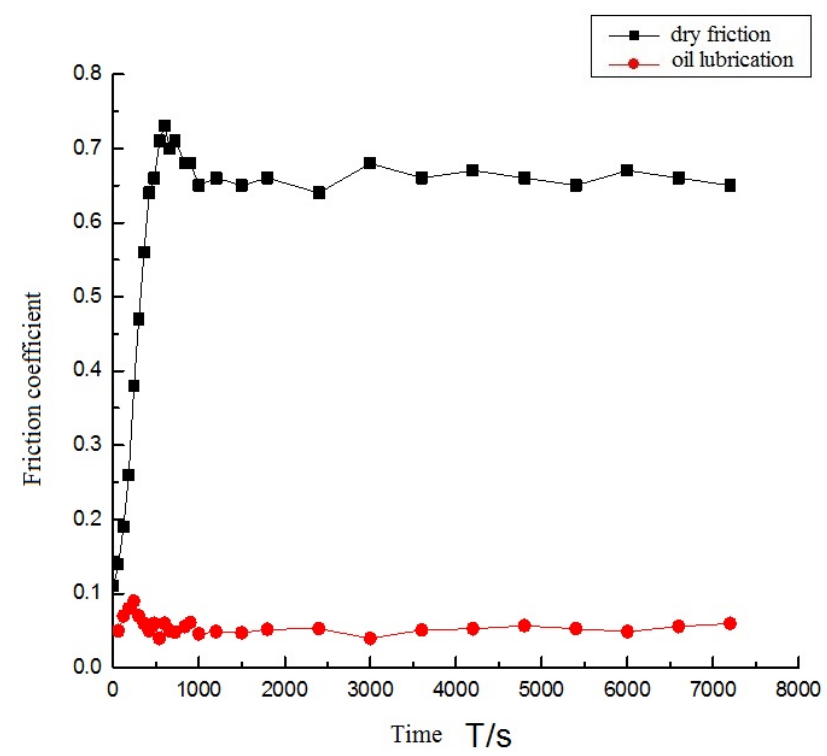

Fig. (2). Curve of friction coefficient and friction pair temperature change under dry friction condition and oil lubrication condition. 
(a) Wear value under dry friction condition

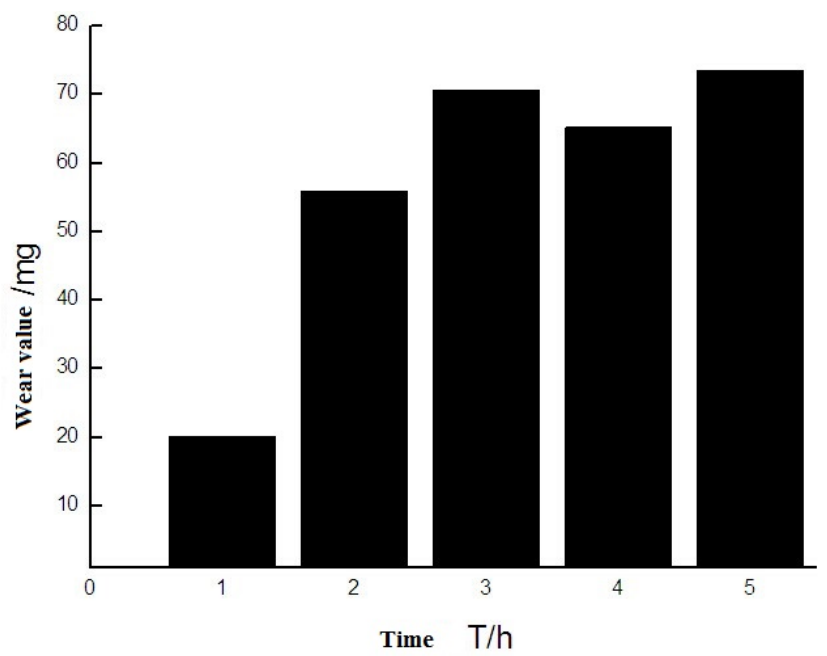

(b) Wear value under oil lubrication condition

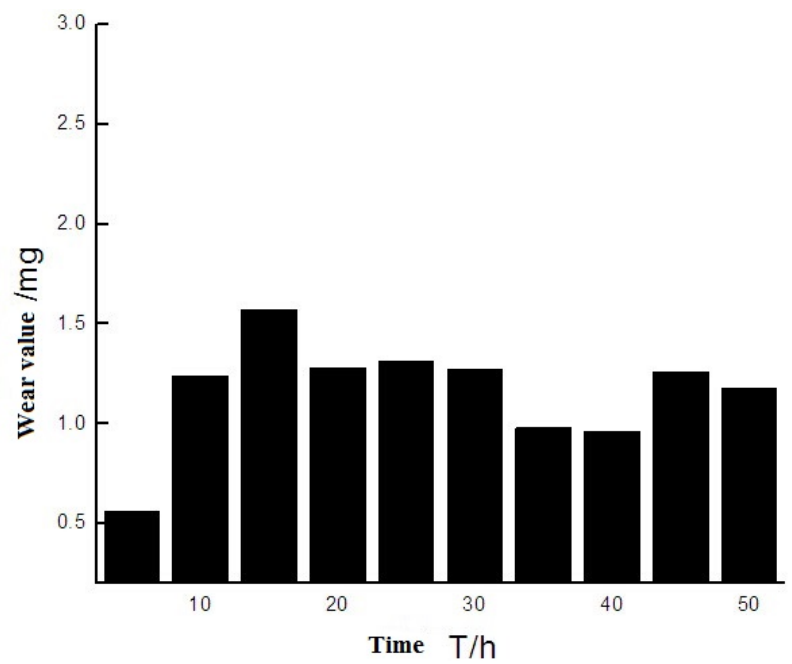

Fig. (3). Wear value change under dry friction condition and oil lubrication condition.

(a) Surface roughness under dry friction condition

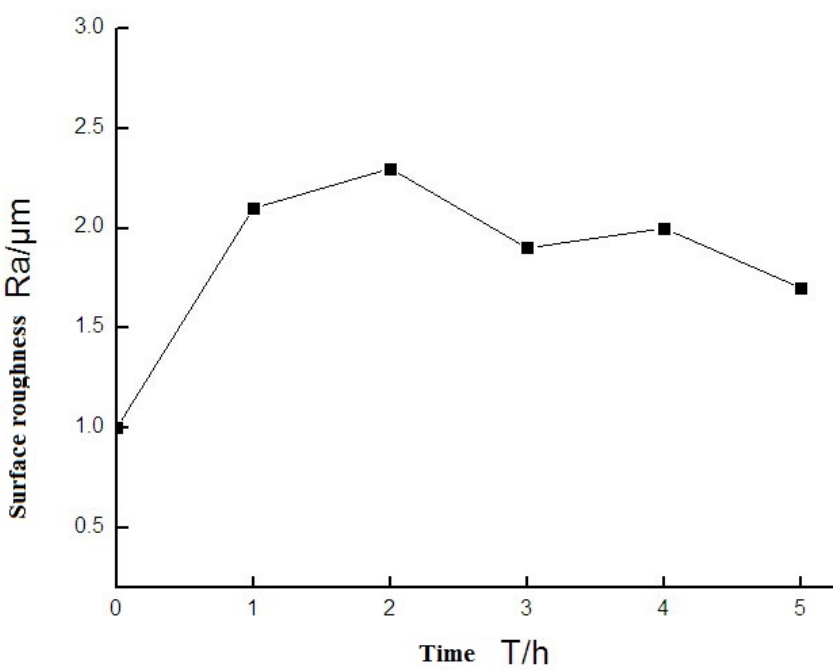

(b) Surface roughness under oil lubrication condition

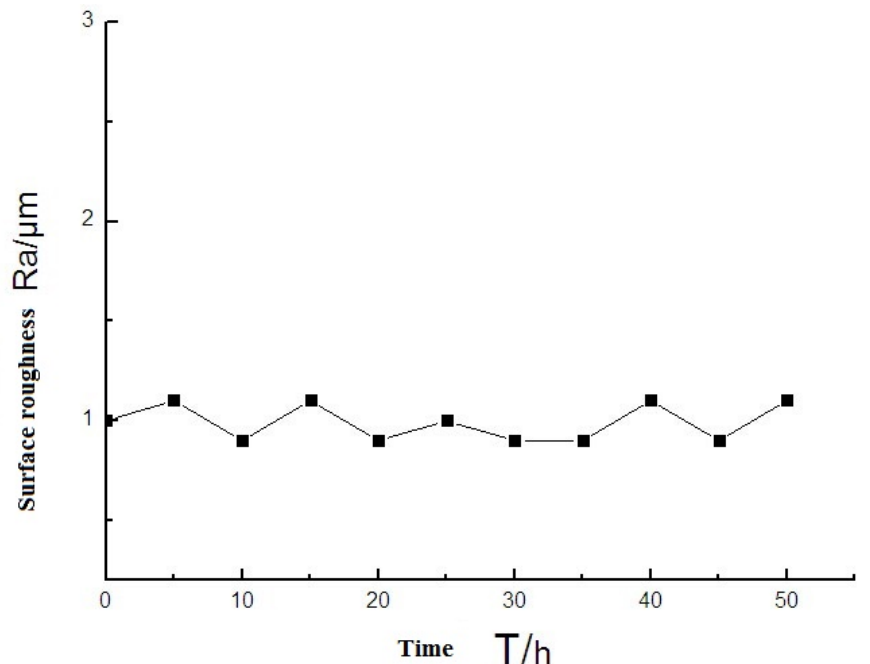

Fig. (4). Surface roughness value change under dry friction condition and oil lubrication condition.

under coupling of rolling and sliding. Fig. (5a) shows the surface morphology of $20 \mathrm{CrMnTi}$ after 1 hour of upper sample experiment under dry friction condition. Due to the direct contact of the contact surface, the asperity on the surface bear great compressive stress, resulting in small and slight plastic flow from top to bottom along rolling and sliding direction, meanwhile, and colored ochre [Fig. (5a) inside the ellipse], and oxidation wear is found on the sample with thin sheet metal plate separation on the surface or embrittlement tendency of metal plate [see Fig. (5a) inside the square], which belongs to the slight fatigue pitting and fatigue spalling. Fig. (5b) shows surface morphology of 20 CrMnTi after 2 hours of upper sample experiment under dry friction condition. As time goes on, typical morphology of friction fatigue such as groove and small cavities can be seen on the surface, and thin and irregular shaped abrasive dusts also can be seen in some region [Fig. (5b) inside the ellipse] and it is formed from the tearing material from the surface in the adhesive wear. Fig. (5c) shows surface morphology of 20 CrMnTi after 4 hours of upper sample experiment under dry friction condition. No clear direction in the wear and large pieces spalling of abrasive dusts can be seen [see Fig. (5c) inside the ellipse], and ochre areas increase, due to the internal crack on the parallel rolling surface and continual oxidation wear. Fig. (5d) shows surface morphology of 20 CrMnTi after 20 hours of upper sample experiment under oil lubrication condition. Many small scratches and minor abrasive dusts can be seen on the surface. According to Fig. (5a-c), this paper argues that under coupling of rolling and sliding, friction and wear is obviously found in steel-steel couples friction pair, and wear fatigue damage mechanism is more complex. 
(a) 1 hour dry friction

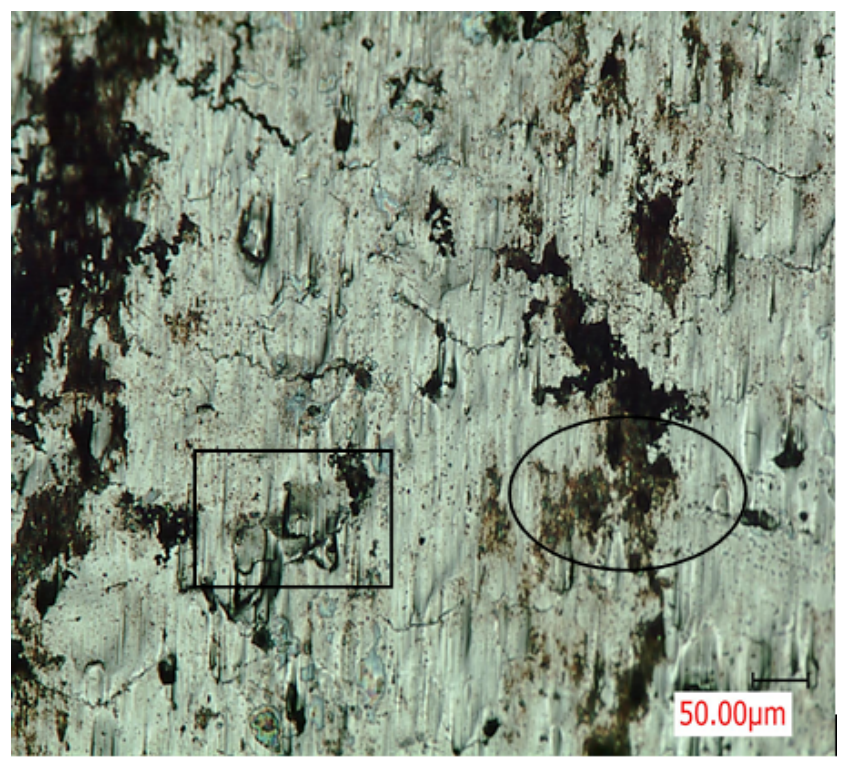

(c) 4 hours dry friction

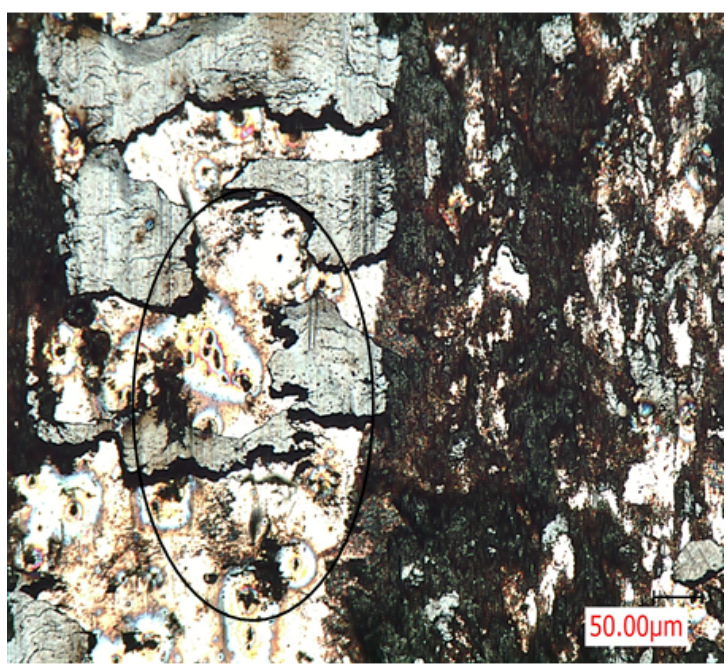

(b) 2 hours dry friction

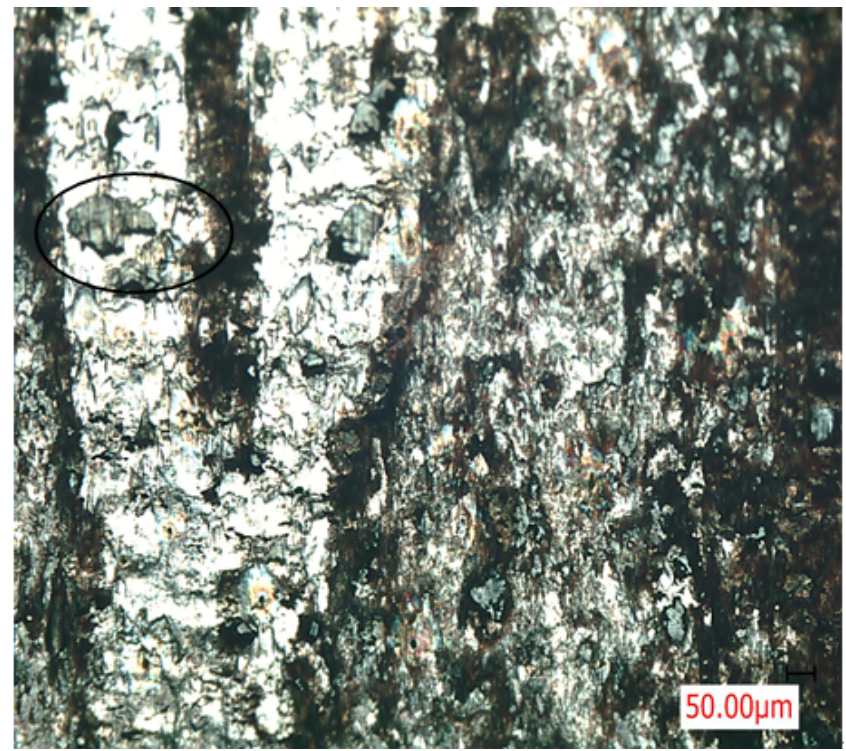

(d) 20 hours dry friction

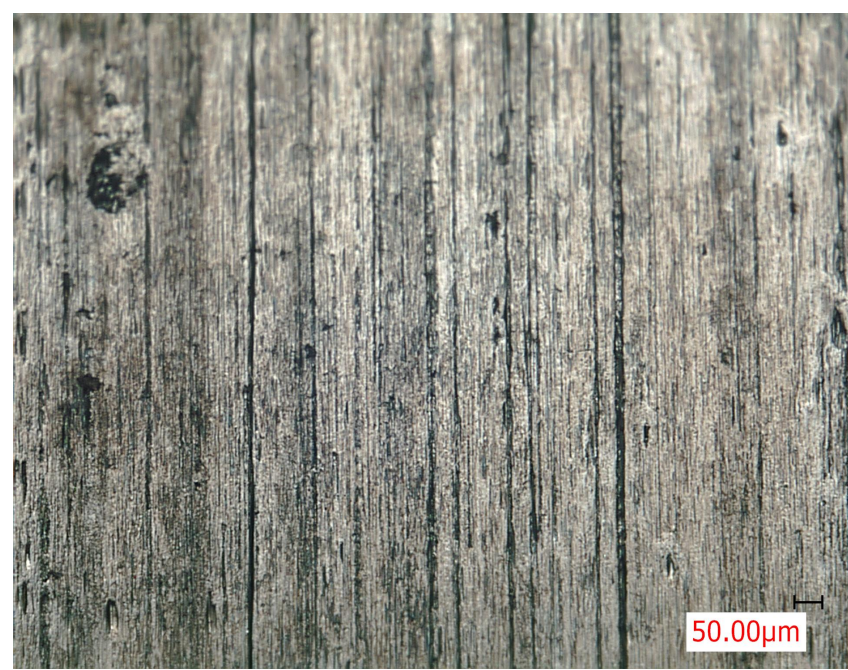

Fig. (5). Wear morphology under dry friction condition and oil lubrication condition $(\times 1000)$.

\section{CONCLUSION}

Damage of steel-steel couples under coupling of rolling and sliding is caused by the interaction of mechanical fatigue with dynamical phenomena of rolling and sliding friction. Lubrication directly determines the friction and wear behaviors of $20 \mathrm{CrMnTi}$ gear steel. Under dry friction, 20 CrMnTi gear steel mainly has adhesive wear, abrasive wear, oxidation wear and fatigue pitting. Under oil lubrication conditions, $20 \mathrm{CrMnTi}$ gear steel mainly has surface fatigue wear. The boundary lubrication of the low speed and heavy load gear should be strengthened with the lubrication oil containing extreme pressure and antiwear additives to improve the boundary films strength and the lubrication state, to avoid the direct contact between the tooth surface, to reduce the gear fatigue wear damage and to prolong operating life.

\section{CONFLICT OF INTEREST}

The author confirms that this article content has no conflict of interest.

\section{ACKNOWLEDGEMENTS}

Declared none. 


\section{REFERENCES}

[1] Z. Zhang, Gear Failure and Counter Measures, China Machine Press, Beijing, 2001.

[2] L.A. Sosnovskiy, and G. Wanzhen, "Tribo-fatigue", In: Proceedings of $3^{\text {rd }}$ International Symposium on Tribo-Fatigue, Beijing, 2000, pp. 1-11.

[3] Q. Li, H. Ma, and G. Zhang, Mining Machinery, China University of Mining and Technology Press, Xuzhou, 2011.

[4] S. Ge, H. Zhu, and G. Li, "Study on wear failures of mining machinery", Tribology, vol. 31, no. 3, pp. 80-385, 2006.
[5] L. Zhu, and X. Zhu, "Experimental study of low-speed heavy wear and gear", Chinese Journal of Mechanical Engineering, vol. 31, no. 3, pp. 3-78, 1995.

[6] S. Ge, D. Zhang, and J. Qin, "Tribology design of boring machine main reducer" Tribology, vol. 22, no. 1, pp. 85-89, 1997.

[7] X. Zhu, and Y. Shao, "Tooth surface hardness of coal low gear and wear properties of heavy-duty impact", Journal of Mechanical Transmission, vol. 26, no. 2, pp. 57-59, 2002.

[8] W. Liu, Q. Xue, and N. Han, "Effects of friction coefficient on the gear contact fatigue life", Journal of Mechanical Transmission, vol. 26, no. 1, pp. 48-49, 2002.

(C) Ding Ming; Licensee Bentham Open.

This is an open access article licensed under the terms of the (https://creativecommons.org/licenses/by/4.0/legalcode), which permits unrestricted, non-commercial use, distribution and reproduction in any medium, provided the work is properly cited. 